\title{
Dependence of the $P_{2}-S_{2}$ stereochemical selectivity of papain on the nature of the catalytic-site chemistry
}

\author{
Quantification of selectivity in the catalysed hydrolysis of the enantiomeric \\ $N$-acetylphenylalanylglycine 4-nitroanilides
}

\author{
Devanand KOWLESSUR,* Emrys W. THOMAS, $\dagger$ Christopher M. TOPHAM,* $\ddagger$ William TEMPLETON* and \\ Keith BROCKLEHURST*§ \\ *Department of Biochemistry, Medical College of St. Bartholomew's Hospital, University of London, Charterhouse Square, \\ London EC1M 6BQ, U.K. and †Department of Biological Sciences, University of Salford, Salford M5 4WT, U.K.
}

\begin{abstract}
1. $N$-Acetyl-L-phenylalanylglycine 4-nitroanilide and its D-entantiomer were synthesized and characterized and used as substrates with which to evaluate stereochemical selectivity in papain (EC 3.4.22.2)-catalysed hydrolysis. 2. Kinetic analysis at pH 6.0, I 0.1, 8.3\% (v/v) $N N$-dimethylformamide and $25^{\circ} \mathrm{C}$ by using initial-rate data with [S] $\ll K_{\mathrm{m}}$ and weighted non-linear regression provided values of $k_{\text {cat. }} / K_{\mathrm{m}}$ for the catalysed hydrolysis of both enantiomers as $\left(k_{\text {cat. }} / K_{\mathrm{m}}\right)_{\mathrm{L}}=2040 \pm 48 \mathrm{M}^{-1} \cdot \mathrm{s}^{-1}$ and $\left(k_{\text {cat. }} / K_{\mathrm{m}}\right)_{\mathrm{D}}=$ $5.9 \pm 0.07 \mathrm{M}^{-1} \cdot \mathrm{s}^{-1}$. These data, taken together with individual values of $k_{\text {cat. }}$ and $K_{\mathrm{m}}$ for the hydrolysis of the L-enantiomer $(a)$ estimated in the present work as $k_{\text {cat. }}=3.2 \pm 1.2 \mathrm{~s}^{-1}$ and $K_{\mathrm{m}}=1.5 \pm 0.6 \mathrm{~mm}$ and $(b)$ reported by Lowe \& Yuthavong [(1971) Biochem. J. 124, 107-115] for the reaction at $\mathrm{pH} 6.0$ in $10 \%(\mathrm{v} / \mathrm{v}) \mathrm{NN}$ dimethyformamide and $35^{\circ} \mathrm{C}$, as $k_{\text {cat. }}=1.3 \pm 0.2 \mathrm{~s}^{-1}$ and $K_{\mathrm{m}}=0.88 \pm 0.1 \mathrm{mM}$, suggest that $\left(k_{\text {cat. }} / K_{\mathrm{m}}\right)_{\mathrm{L}} \simeq$ $2000 \mathrm{M}^{-1} \cdot \mathrm{s}^{-1}$ and thus that $\left(k_{\text {cat. }} / K_{\mathrm{m}}\right)_{\mathrm{L}} /\left(k_{\text {cat. }} / K_{\mathrm{m}}\right)_{\mathrm{D}} \simeq 330.3$. Model building indicates that both enantiomeric 4-nitroanilides can bind to papain such that the phenyl ring of the $N$-acetylphenylalanyl group makes hydrophobic contacts in the $S_{2}$ subsite with preservation of mechanistically relevant hydrogen-bonding interactions and that the main difference is in the positioning of the $\beta$-methylene group. 4 . The dependence of $\mathrm{P}_{2}-\mathrm{S}_{2}$ stereochemical selectivity of papain on the nature of the catalytic-site chemistry for reactions involving derivatives of $\mathrm{N}$-acetylphenylalanine is discussed. The variation in the index of stereochemical selectivity (ratio of the appropriate kinetic or thermodynamic parameter for a given pair of enantiomeric ligands), from 330 for the overall acylation process of the catalytic act, through 40 and 31 for the reaction at electrophilic sulphur in 2-pyridyl disulphides respectively without and with assistance by (His159)- $\mathrm{Im}^{+}-\mathrm{H}$, to 5 for the formation of thiohemiacetal adducts by reaction at aldehydic carbon, is interpreted in terms of the extent to which conformational variation of the bound ligand in the catalytic-site region permits the binding mode of the $-\mathrm{CH}_{2}-\mathrm{Ph}$ group of the D-enantiomer to approach that of the L-enantiomer.
\end{abstract}

\section{INTRODUCTION}

As part of an investigation of the nature of the interdependence of catalytic-site chemistry in papain (EC 3.4.22.2) and molecular recognition involving non-scissile parts of substrates (Brocklehurst et al., 1988a,b), we reported a relatively low level of discrimination of this enzyme for the enantiomeric $2-\left(N^{\prime}\right.$-acetylphenylalanylamino)ethyl 2'-pyridyl disulphides (compounds I and II) (Templeton et al., 1990). Thus (i) papain reacts with the D-enantiomer (compound I) only 30-60-fold more slowly than with the L-enantiomer (compound II) and (ii), of particular note, the same shape of the $\mathrm{pH}-k$ profile characteristic of efficient signalling from binding area to catalytic site to provide for substantial contribution of an $-\mathrm{Im}^{+}-\mathrm{H}$-assisted transition state is observed for reactions of both enantiomers. These findings and their assessment by model building support the conclusion reached by Mackenzie et al. (1986) from studies on the binding to papain of the enantiomeric $\mathrm{N}$-acetylphenylalanylglycinals (compounds III and IV) that the $\mathrm{S}_{2}$ subsite of papain does not always exert absolute specificity for $N$-acetylphenylalanine residues. This conclusion appears to contradict indications in the older literature [see Lowe (1976) and Brocklehurst et al. (1987b) for reviews] that papain exerts a high or even an absolute specificity for L-amino acid residues in the $\mathrm{P}_{2}$ position (Berger \& Schechter, 1970) in substrates and inhibitors, although the difference in catalytic efficiency of papain towards enantiomeric substrates does not appear to have been quantified.

In the present work the enantiomeric $N$-acetylphenylalanylglycine 4-nitroanilides (compounds $\mathrm{V}$ and VI) were synthesized and characterized and used as

Abbreviations used: Boc, t-butyloxycarbonyl; DMF, $N N$-dimethylformamide.

$\ddagger$ Present address: Department of Crystallography, Birkbeck College, University of London, Malet Street, London WC1E 7HX, U.K.

$\S$ To whom correspondence and requests for reprints should be addressed.

Vol. 266 
<smiles>CC(=O)NC(C)C(=O)NCCSSc1ccccc1</smiles>

(I) L-Enantiomer

(II) D-Enantiomer<smiles>CC(=O)NC(Cc1ccccc1)C(=O)NCC=O</smiles>

(III) L-Enantiomer

(IV) D-Enantiomer

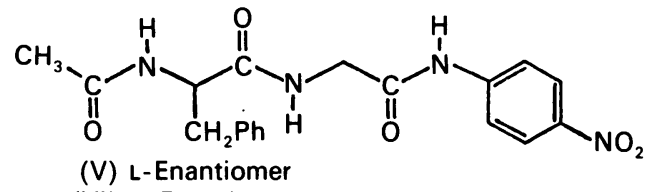

(VI) D-Enantiomer

substrates for papain at $\mathrm{pH} 6.0$ under conditions where, for each, [S] $\ll K_{\mathrm{m}}$.

The more effective discrimination of papain between the enantiomeric 4-nitroanilide substrates, where $\left(k_{\text {cat. }} / K_{\mathrm{m}}\right)_{\mathrm{L}} /\left(k_{\text {cat. }} / K_{\mathrm{m}}\right)_{\mathrm{D}}$ is approx. 330 , than between the enantiomeric 2-pyridyl disulphides (where the ratio of reactivities is 30-60) and between the enantiomeric aldehydes (where the ratio of the binding constants is 5) is discussed.

\section{MATERIALS AND METHODS}

\section{Materials}

Papain. The isolation of papain by a procedure involving covalent chromatography was performed as indicated by Templeton et al. (1990).

Enantiomeric $\boldsymbol{N}$-acetyl-Phe-Gly 4-nitroanilides. To a solution of glycine 4-nitroanilide (Sigma Chemical Co.) $(5 \mathrm{mmol})$ in dry DMF at $0{ }^{\circ} \mathrm{C}$ was added Boc-Phe $\mathrm{N}$ hydroxysuccinimide ester (Sigma Chemical Co.) (either L- or $\mathrm{D}-; 5 \mathrm{mmol}$ ) portionwise with stirring. After the reaction mixture had been left to stand at $4{ }^{\circ} \mathrm{C}$ for $12 \mathrm{~h}$, Boc-Phe-Gly 4-nitroanilide was precipitated by addition of an excess of ice-cold water. The product was isolated by filtration, washed with water and air-dried. Removal of the Boc group was effected by dissolution in formic acid $(30 \mathrm{ml})$ and storage at $25^{\circ} \mathrm{C}$ for $12 \mathrm{~h}$. Removal of the formic acid in vacuo left a crystalline residue (presumably the formate salt of Phe-Gly 4-nitroanilide), which was dissolved in DMF $(10 \mathrm{ml}) . \alpha-N$-Acetylation was effected by addition of ethyl di-isopropylamine (5.5 $\mathrm{mmol})$ followed by acetic anhydride $(5.5 \mathrm{mmol})$ at $15^{\circ} \mathrm{C}$. After $30 \mathrm{~min}, \mathrm{~N}$-acetyl-Phe-Gly 4-nitroanilide (approx. $1.6 \mathrm{~g}$ ) was precipitated by addition of an excess of icecold water, isolated by filtration and air-dried. The solid was suspended in boiling ethanol $(150 \mathrm{ml})$, and the minimum quantity of DMF to effect solution was added. On cooling to $4{ }^{\circ} \mathrm{C}$, the product crystallized and $1.2-1.5 \mathrm{~g}$ was isolated. Both D- and L-enantiomers had m.p. $235^{\circ} \mathrm{C}$ [Lowe \& Yuthavong (1971a) give m.p. $221-223^{\circ} \mathrm{C}$ for the L-enantiomer recrystallized from acetone/diethyl ether/light petroleum (b.p. $60-80^{\circ} \mathrm{C}$ )]. Optical rotation data: $[\alpha]_{\mathrm{D}}^{20}+9.87^{\circ}$ for the L-enantiomer and $-9.92^{\circ}$ for the D-enantiomer (in both cases $c 0.012$ in DMF) [Lowe \& Yuthavong $(1971 a)$ give $[\alpha]_{\mathrm{D}}^{20}+117^{\circ}(c 0.3$ in DMF) for the L-enantiomer; see the Results and discussion section]. Spectroscopic data: (a) u.v. data (in ethanol), $\lambda_{\max } 313 \mathrm{~nm}$ for both enantiomers, $\epsilon_{313} 14800 \mathrm{M}^{-1} \cdot \mathrm{cm}^{-1}$ for the L-enantiomer and $14930 \mathrm{M}^{-1} \cdot \mathrm{cm}^{-1}$ for the Denantiomer [Lowe \& Yuthavong (1971a) give $\lambda_{\max }$. $313 \mathrm{~nm}$ and $\epsilon_{313} 13300 \mathrm{M}^{-1} \cdot \mathrm{cm}^{-1}$ for the L-enantiomer]; (b) n.m.r. data (300 MHz) for the L-enantiomer, $\delta$ (p.p.m.) ( $\left[{ }^{2} \mathrm{H}_{6}\right]$ dimethyl sulphoxide) $1.8\left(3 \mathrm{H}, \mathrm{s}, \mathrm{CH}_{3} \mathrm{CO}\right), 3.75(2 \mathrm{H}$, d, Gly-C $\left.\mathrm{CH}_{2}\right), 3.95\left(2 \mathrm{H}, \mathrm{m}\right.$, Phe- $\left.\mathrm{CH}_{2}\right), 4.50(1 \mathrm{H}, \mathrm{m}$, Phe$\mathrm{CH}), 7.2(1 \mathrm{H}, \mathrm{m}, \mathrm{NH}), 7.25(5 \mathrm{H}, \mathrm{m}$, phenylalanine ring), 7.85 and $8.25(2 \mathrm{H}$, both $\mathrm{d}$, nitroaniline ring), $8.5(1 \mathrm{H}, \mathrm{t}$, $\mathrm{N} H)$ and $10.55(1 \mathrm{H}, \mathrm{s}, \mathrm{N} H)$. Analysis by chromophore release: both enantiomers released the expected amount of 4-nitroaniline (see below) consequent upon complete hydrolysis catalysed by papain at $\mathrm{pH} 6.0$ and reaction occurred in single-phase progress curves, that for the L-enantiomer being very much faster than that for the D-enantiomer.

\section{Kinetics}

Initial rates of release of 4-nitroaniline from the enantiomeric 4-nitroanilide substrates at $25^{\circ} \mathrm{C}$ in sodium phosphate buffer, $\mathrm{pH} 6.0$, containing $8.3 \%$ (v/v) DMF with $[\mathrm{E}]=0.5-2.0 \mu \mathrm{M}$ and $[\mathrm{S}]$ approx. $20-170 \mu \mathrm{M}$ for the D-enantiomer and approx. $20-220 \mu \mathrm{M}$ for the Lenantiomer were determined at $410 \mathrm{~nm}$ by using a Cary $118 \mathrm{C}$ spectrophotometer and quantified by using $\Delta \epsilon_{410}=$ $8.8 \times 10^{3} \mathrm{M}^{-1} \cdot \mathrm{cm}^{-1}$ (Erlanger et al., 1961). Non-enzymic hydrolysis of the 4-nitroanilides could not be detected. Active-site titration of papain was carried out by using 2,2'-dipyridyl disulphide at $\mathrm{pH} 4.0$ as described by Brocklehurst \& Little (1973).

\section{Data processing}

Kinetic data ([S], $v$ pairs) were fitted to rate equations by using weighted non-linear-regression analysis using the AR computer program (1988 PC version) from the BMDP statistical software package (Dixon et al., 1988) and a Compaq Deskpro 386/20e PC and displayed by using a Hewlett-Packard Colour Pro Plotter. Constant relative error was assumed with weights inversely proportional to $v^{\mathrm{s}}$. For the catalysed hydrolysis of the Lenantiomer with [S] approx. 20-240 mM, the data were fitted to the Michaelis-Menten equation. For the catalysed hydrolysis of the D-enantiomer with [S] approx. $20-170 \mu \mathrm{M}$ and for that of the L-enantiomer with [S] approx. $20-45 \mu \mathrm{M}$, the data were fitted to $(v /[\mathrm{E}])=$ $\left(k_{\text {cat. }} / K_{\mathrm{m}}\right)[\mathrm{S}]$.

\section{RESULTS AND DISCUSSION \\ Synthesis and characteristics of the enantiomeric $\boldsymbol{N}$-acetyl-Phe-Gly 4-nitroanilides}

In the present work, both enantiomers were synthesized by allowing glycine 4-nitroanilide to react with the appropriate Boc-Phe $N$-hydroxysuccinimide ester with subsequent removal of the Boc protecting group and acetylation of the freed $\alpha$-amino group by acetic anhydride. Lowe \& Yuthavong (1971a) synthesized the L-enantiomer by reaction of $N$-acetyl-L-Phe-Gly with ethyl chloroformate and subsequent reaction of 4-nitroaniline with the intermediate mixed anhydride. The L- 
enantiomer produced in the present work and crystallized from ethanol/DMF (a) has m.p. $235^{\circ} \mathrm{C}$, which is $13{ }^{\circ} \mathrm{C}$ higher than the value reported by Lowe \& Yuthavong (1971a) for their product, which was recrystallized from acetone/diethyl ether/light petroleum (b.p. $60-80^{\circ} \mathrm{C}$ ), and $(b)$ has $[\alpha]_{\mathrm{D}}^{20}+9.87^{\circ}(c 0.012$ in DMF), which is considerably smaller than the value $+117^{\circ}(c 0.3$ in DMF) reported by Lowe \& Yuthavong (1971a). There are no obvious and convincing explanations for these discrepancies. A difference in melting point might be attributed to different crystal forms, and a possible explanation for the large discrepancy in the reported values of the specific rotation for the L-enantiomer is that a value of $+11.7^{\circ}$ might have been wrongly recorded as $+117^{\circ}$, although $+117^{\circ}$ is the value recorded in Dr. Yuthavong's D.Phil. Thesis (personal communication from Professor G. Lowe, University of Oxford). The value of $[\alpha]_{D}^{20}\left(-9.92^{\circ}\right)$ for the D-enantiomer determined in the present work demonstrates close similarity in the optical purities of both enantiomers. The n.m.r. data reported in the Materials and methods section are consistent with the assignment of the expected structure to compound (V), and the results of the chromophore release experiments for the complete papain-catalysed hydrolysis of both enantiomers (compounds V and VI) (expected stoichiometries, single-phase progress curves and considerably different rates) appear to rule out significant contamination of one enantiomer with the other.

\section{Assessment of the influence of $P_{2}$-chirality on the effectiveness of papain-catalysed hydrolysis of the $\mathrm{N}$-acetyl-Phe-Gly 4-nitroanilides at pH 6.0}

The assessment was made by comparing the values of $k_{\text {cat. }} / K_{\mathrm{m}}$ for the papain-catalysed hydrolysis of the enantiomeric anilides at $\mathrm{pH} 6.0$, which is in the $\mathrm{pH}$ region where $k_{\text {cat. }} / K_{\mathrm{m}}$ is maximal for the catalysed hydrolysis of compound (V) (Lowe \& Yuthavong, 1971b) and of many other substrates (see Brocklehurst et al., $1987 b)$. The specificity constant, $k_{\text {cat. }} / K_{\mathrm{m}}$ (Fersht, 1977), is the apparent second-order rate constant for product formation from reaction of enzyme and substrate. It is not affected by non-productive binding (Bender \& Kézdy, 1965; Brocklehurst et al., 1968), a phenomenon that can sometimes complicate mechanistic studies on reactions of proteinases with analogue substrates, and is a valuable parameter with which to evaluate enzyme effectiveness (see, e.g., Brocklehurst \& Cornish-Bowden, 1976; Brocklehurst, 1977). When the value of $k_{\text {cat. }} / K_{\mathrm{m}}$ is well below the lower limit of the value of the second-order rate constant for formation of the Michaelis complex (ES) (arguably approx. $1 \times 10^{7} \mathrm{M}^{-1} \cdot \mathrm{s}^{-1}$ ), a necessary consequence is that the conventional condition for the existence of quasi-equilibrium $\left[k_{+2} \ll k_{-1}\right.$; see the threestep acyl-enzyme model, eqn. (1)] applies (Brocklehurst, 1979):

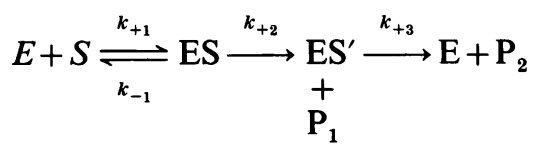

Then $k_{\text {cat. }} / K_{\mathrm{m}}$ represents the apparent second-order rate constant for the overall acylation process, $k_{+2} / K_{\mathrm{s}}(=$ $\left.k_{+1} k_{+2} / k_{-1}\right)$. For the papain-catalysed hydrolysis of compounds (V) and (VI) the values of $k_{\text {cat. }} / K_{\mathrm{m}}$ are well
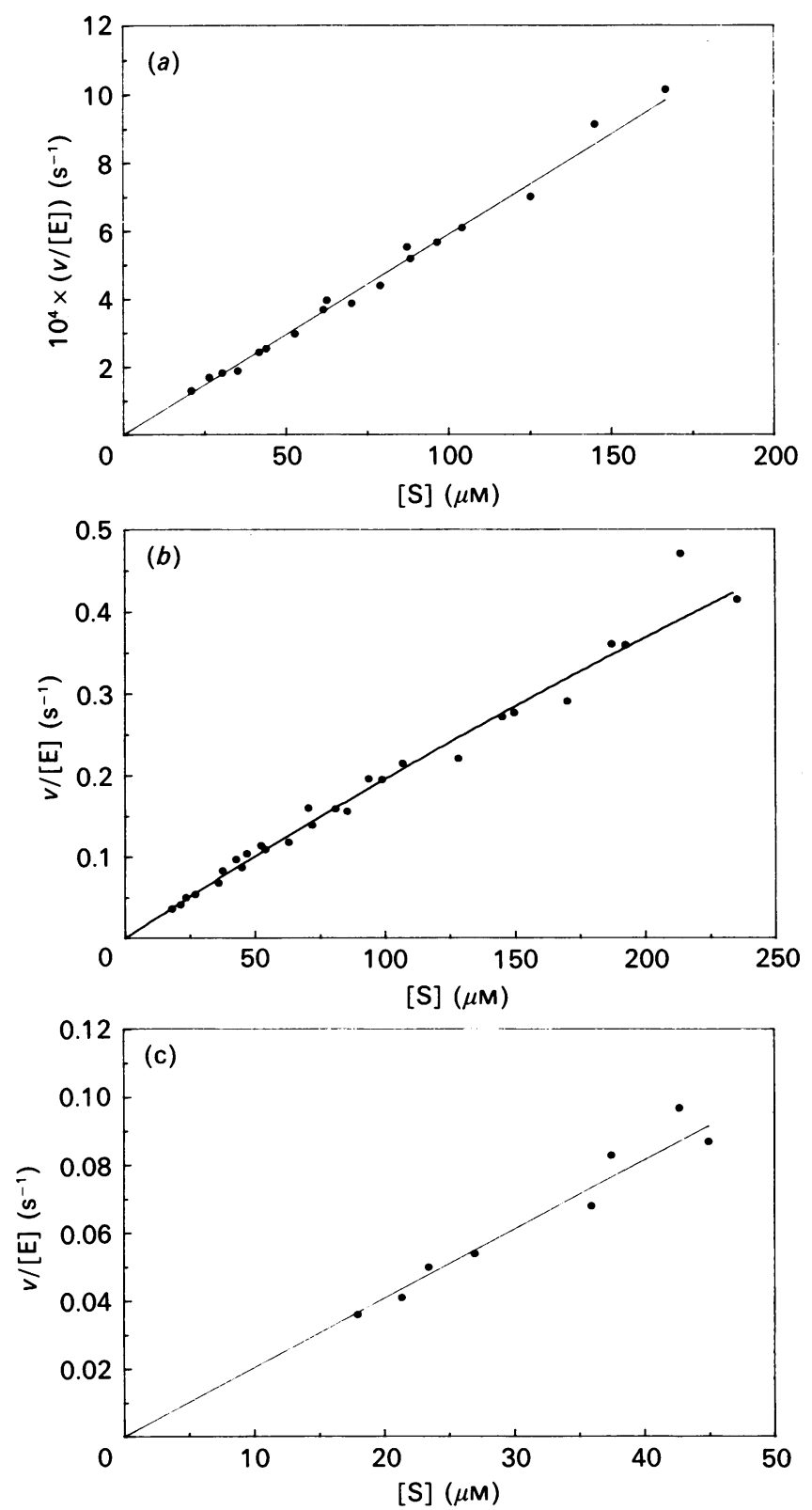

Fig. 1. Dependence on substrate concentration ([S]) of the initial rate ( $v$ )(plotted as $v /[E]$ ) of the papain-catalysed hydrolysis of (a) $\mathrm{N}$-acetyl-D-Phe-Gly 4-nitroanilide and $(b)$ and (c) its L-enantiomer in sodium phosphate buffer, pH 6.0 and I 0.1, containing $8.3 \%(\mathrm{v} / \mathrm{v}) \mathrm{DMF}$ at $25^{\circ} \mathrm{C}$

The points are experimental and the continuous lines are theoretical for the rate equations given below and best-fit values of the kinetic parameters determined by weighted non-linear-regression analysis as described in the Materials and methods section and the footnote to Table 1: for (a) $v /[\mathrm{E}]=\left(k_{\text {cat. }} / K_{\mathrm{m}}\right)[\mathrm{S}]$, where $k_{\text {cat. }} / K_{\mathrm{m}}=5.9 \mathrm{M}^{-1} \cdot \mathrm{s}^{-1}$; for (b) $v /[\mathrm{E}]=k_{\text {cat. }}[\mathrm{S}] /\left(K_{\mathrm{m}}+[\mathrm{S}]\right)$, where $k_{\text {cat. }}=3.182 \mathrm{~s}^{-1}$ and $K_{\mathrm{m}}=1.534 \mathrm{mM}$; for $(c) v /[\mathrm{E}]=\left(k_{\text {cat. }} / K_{\mathrm{m}}\right)[\mathrm{S}]$, where $k_{\text {cat. }} /$ $K_{\mathrm{m}}^{\mathrm{m}}=2040 \mathrm{M}^{-1} \cdot \mathrm{s}^{-1}$.

below $1 \times 10^{7} \mathrm{M}^{-1} \cdot \mathrm{s}^{-1}$ (see Table 1) and therefore are reasonably considered good estimates of $k_{+2} / K_{\mathrm{s}}$.

The linear dependence of $v /[\mathrm{E}]$ on $[\mathrm{S}]$ for the papaincatalysed hydrolysis of the D-enantiomer (compound VI) at values of [S] up to the solubility limit (approx. $170 \mu \mathrm{M}$ ) 
Table 1. Kinetic parameters for the papain-catalysed hydrolysis of the enantiomeric $\boldsymbol{N}$-acetyl-Phe-Gly 4-nitroanilides at pH 6.0

Abbreviations: N.D., not determined; N.A., not available.

\begin{tabular}{|c|c|c|c|c|c|c|c|}
\hline Enantiomer & $\begin{array}{l}\text { Temper- } \\
\text { ature } \\
\left({ }^{\circ} \mathrm{C}\right)\end{array}$ & Solvent & $\begin{array}{l}\text { Range of } \\
{[\mathrm{S}](\mu \mathrm{M})}\end{array}$ & $\begin{array}{c}k_{\text {cat. }} \pm \text { S.E. } \\
\left(\mathrm{s}^{-1}\right)\end{array}$ & $\underset{(\mathrm{mM})}{K_{\mathrm{m}} \pm \text { S.E. }}$ & $\begin{array}{c}k_{\text {cat. }} / K_{\mathrm{m}} \pm \text { S.E. } \\
\left(\mathrm{M}^{-1} \cdot \mathrm{S}^{-1}\right)\end{array}$ & Reference \\
\hline $\begin{array}{l}\text { L-Enantiomer } \\
\text { L-Enantiomer } \\
\text { D-Enantiomer } \\
\text { L-Enantiomer }\end{array}$ & $\begin{array}{l}25 \\
25 \\
25 \\
35\end{array}$ & $\begin{array}{l}8.3 \% \text { (v/v) DMF } \\
8.3 \% \text { (v/v) DMF } \\
8.3 \% \text { (v/v) DMF } \\
10 \%(\mathrm{v} / \mathrm{v}) \text { DMF }\end{array}$ & $\begin{array}{l}18-235 \\
18-45 \\
21-167 \\
\text { N.A. }\end{array}$ & $\begin{array}{l}3.2 \pm 1.2 \\
\text { N.D. } \\
\text { N.D. } \\
1.3 \pm 0.2\end{array}$ & $\begin{array}{l}1.5 \pm 0.6 \\
\text { N.D. } \\
\text { N.D. } \\
0.88 \pm 0.1\end{array}$ & $\begin{array}{c}2088^{*} \pm 55 \dagger \\
2040 \pm \pm 48 \\
5.9 \pm \pm 0.07 \\
1500 \pm 200\end{array}$ & $\begin{array}{l}\text { Present work } \\
\text { Present work } \\
\text { Present work } \\
\text { Lowe \& Yuthavong } \\
(1971 a)\end{array}$ \\
\hline
\end{tabular}

* Calculated from the best-estimate values of $k_{\text {cat. }}\left(3.182 \mathrm{~s}^{-1}\right)$ and $K_{\mathrm{m}}(1.524 \mathrm{~mm})$.

$\dagger$ The standard error of the value of the ratio [S.E. $\left(k_{\text {cat. }} / K_{\mathrm{m}}\right)$ ] obtained from the best-estimate values of the individual parameters $k_{\text {cat. }}$ and $K_{\mathrm{m}}$ was calculated from

$$
\text { S.E. }\left(k_{\text {cat. }} / K_{\mathrm{m}}\right) \simeq \pm k_{\text {cat. }} / K_{\mathrm{m}} \sqrt{ }\left(c_{\left(k_{\text {cat. }}\right)}{ }^{2}+c_{\left(K_{\mathrm{m}}\right)}{ }^{2}-2 c_{\left(k_{\text {cat. }}\right)} c_{\left(K_{\mathrm{m}}\right)}\right)
$$

where the best estimate of $k_{\text {cat. }} / K_{\mathrm{m}}=2088 \mathrm{M}^{-1} \cdot \mathrm{s}^{-1}, c_{\left(k_{\mathrm{cat}}\right)}=0.3763846, c_{\left(K_{\mathrm{m}}\right)}=0.3983323$ ( $c$ for a given parameter being the coefficient of variation for that parameter, i.e. the s.E. expressed as a fraction of the mean) and $\rho=0.993$ ( $\rho$ being correlation between $k_{\text {eat. }}$ and $K_{\mathrm{m}}$, which is a normalized form of the co-variance; see Wilkinson, 1961). Values of $c_{\left(k_{\text {cat. }}\right)}, c_{\left(K_{\mathrm{m}}\right)}$ and $\rho$ are provided in the computer from the BMDP statistical package used to carry out the weighted non-linear-regression analysis (see the Materials and methods section).

$\ddagger$ Value of the ratio obtained directly from the linear plots of $v$ versus [S] with $[\mathrm{S}] \ll K_{\mathrm{m}}$.

and of the L-enantiomer (compound V) at values of [S] up to approx. $45 \mu \mathrm{M}$ is shown in Fig. 1. Fig. 1 shows also that for the catalysed hydrolysis of the L-enantiomer extending the substrate concentration up to approx. $230 \mu \mathrm{M}$ (the solubility limit) produces shallow curvature in the plot of $v /[\mathrm{E}]$ versus [S]. This curvature is sufficient to permit estimates of the individual parameters $k_{\text {cat. }}$ and $K_{\mathrm{m}}$ to be obtained by using the BMDP statistical software package to carry out non-linear-regression analysis. The values of $k_{\text {cat. }}$ and $K_{\mathrm{m}}$ for the catalysed hydrolysis of the L-enantiomer and of $k_{\text {cat. }} / K_{\mathrm{m}}$ for the catalysed hydrolysis of both enantiomers with associated standard errors are recorded in Table 1 . The convention suggested by Wilkinson (1961) is followed, whereby the square root of the variance is termed the standard error (S.E.; see Table 1) when the precision of a statistic, such as a regression coefficient, as an estimate of a parameter is being referred to. Standard error, which should not be confused with standard error of the mean (S.E.M.), is identical numerically with standard deviation, which is used to describe variability in experimental data.

As expected from the small amount of curvature in Fig. 1(b), the standard errors on the individual parameters are high (for $k_{\text {cat. }}$ the coefficient of variation $c=$ 0.375 , and for $K_{\mathrm{m}} c=0.4$ ). The value of $k_{\text {cat. }} / K_{\mathrm{m}}$ obtained from the individual parameters, however $\left(2088 \pm 155 \mathrm{M}^{-1} \cdot \mathrm{s}^{-1}, \quad c=0.026\right)$, is similar to that $\left(2040 \pm 48 \mathrm{M}^{-1} \cdot \mathrm{s}^{-1}, c=0.024\right)$ obtained from Fig. 1(c), where the range of [S] is sufficiently below $K_{\mathrm{m}}$ to provide a good approximation to linearity in the plot of $v /[\mathrm{E}]$ versus [S], with a similar standard error. Consideration of the kinetic data here reported together with those reported by Lowe \& Yuthavong (1971a) (see Table 1) suggests that for the papain-catalysed hydrolysis of the L-enantiomer (compound V) $K_{\mathrm{m}} \simeq 1 \mathrm{mM}, k_{\text {cat. }} \simeq 2 \mathrm{~s}^{-1}$ and $k_{\text {cat. }} / K_{\mathrm{m}} \simeq 2000 \mathrm{M}^{-1} \cdot \mathrm{s}^{-1}$, whereas for the catalysed hydrolysis of the D-enantiomer (compound VI) $k_{\text {cat. }} / K_{\mathrm{m}}$ $\simeq 6 \mathrm{M}^{-1} \cdot \mathrm{s}^{-1}$, and thus $\left(k_{\text {cat. }} / K_{\mathrm{m}}\right)_{\mathrm{L}} /\left(k_{\text {cat. }} / K_{\mathrm{m}}\right)_{\mathrm{D}} \simeq 330$. Thus for this pair of enantiomeric substrates the stereochemical selectivity exerted by papain in favour of the L-enan- tiomer is now more satisfactorily described than in the past, when an essentially absolute selectivity or specificity has usually been assumed. The quantification permits a comparison between the selectivity exerted in the acylation process of the catalytic act and other reactions involving nucleophilic attack of the thiolate anion of the papain catalytic site on different electrophilic centres with different electronic and steric requirements and preferences.

\section{Dependence of $\mathbf{P}_{2}-\mathbf{S}_{2}$ stereochemical selectivity of papain on the nature of the catalytic-site chemistry for reactions involving derivatives of $\boldsymbol{N}$-acetyl-Phe}

The stereochemical selectivities of papain for phenylalanine residues at the $P_{2}$ position of a ligand exerted in four different reactions are compared in Table 2. The index of stereochemical selectivity (ratio of the appropriate kinetic or thermodynamic parameter for a given pair of enantiomeric ligands) varies from 330 for the overall acylation process of the catalytic act, through 40 and 31 for the reaction at electrophilic sulphur in 2pyridyl disulphides respectively without and with assistance by (His-159)- $\mathrm{Im}^{+}-\mathrm{H}$, to 5 for the formation of thiohemiacetal adducts by reaction at aldehydic carbon. Clearly variation in some aspect of the nature of the chemistry occurring in the catalytic site results in considerable variation in the expression of stereochemical selectivity. In general terms it seems that conformational demands of transition-state or adduct geometries may be coupled with binding modes at least as remote as in the $\mathrm{P}_{2}-\mathrm{S}_{2}$ region. Lowe \& Yuthavong (1971a) demonstrated the existence of a relationship between the nature of the electrophilic group of a ligand bound in the catalytic site and the effectiveness of the binding to papain of $N$-acetylaminomethyl-, $N$-benzoylaminomethyl- and $N$-methoxycarbonyl-L-phenylalanine aminomethyl derivatives (nitriles and thioamides). A key result was the much larger decrease in the dissociation binding constants with increase in binding opportunities for the nitriles than for the thioamides. This supported the 
Table 2. Dependence of $\mathrm{P}_{2}-\mathrm{S}_{2}$ stereochemical selectivity of papain on the nature of the catalytic-site chemistry for reactions involving derivatives of $\boldsymbol{N}$-acetyl-Phe

R- $=\mathrm{N}$-acetyl-Phe- $\mathrm{NH}-\mathrm{CH}_{2}-; \mathbf{R}^{\prime}-=\mathrm{N}$-acetyl-Phe-NH- $\mathrm{CH}_{2}-\mathrm{CH}_{2}-$.

Index of stereochemical

selectivity: ratio

of kinetic or thermo-

dynamic parameters

for reactions of a

Reaction

Postulated transition given pair of enantiomers

Reference

(2) Reaction of 2-pyridyl disulphides with the uncomplicated thiolate anion of papain in the $\mathrm{X}$ state at high $\mathrm{pH}$

Acylation of papain<smiles>CCCC[In]PS</smiles>

by 4-nitroanilides

(3) Reaction of 2-pyridyl disulphides with the fully catalytically competent ion-pair of papain (in the $\mathrm{XH}_{2}$ state of the reaction that predominantes at $\mathrm{pH}$ values around 6)

(4) Thiohemiacetal (adduct) formation by reaction of papain with substituted glycinals state [ ] $]^{\ddagger}$ or adduct

$\left.\right|_{\mathrm{Im}^{+} \mathrm{T}^{-}} \frac{\left(k_{+2} / K_{\mathrm{s}}\right)_{\mathrm{L}}^{\dagger}}{\left(k_{+2} / K_{\mathrm{s}}\right)_{\mathrm{D}}}=330 \quad$ Present work

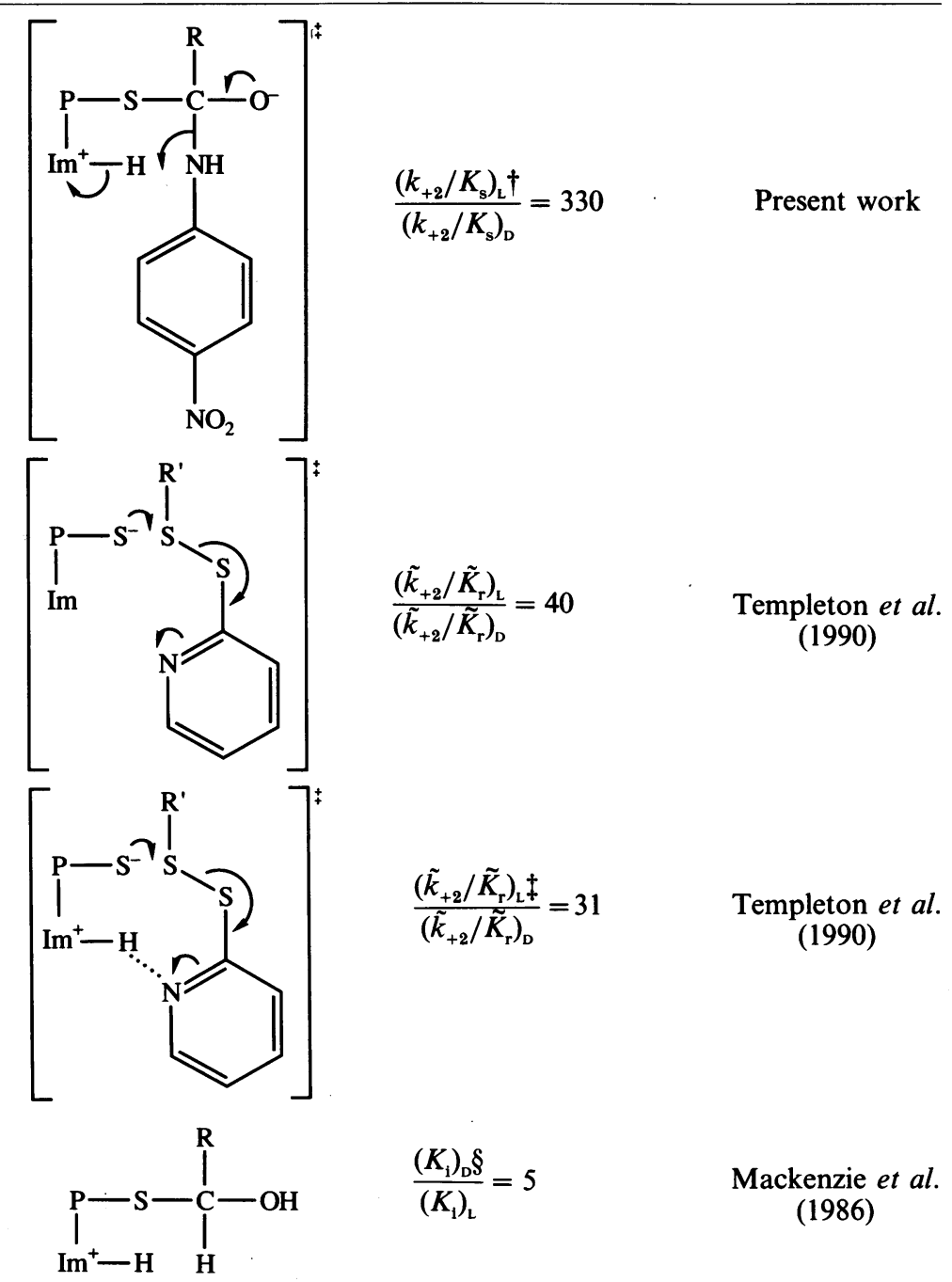

* The inverse kinetic solvent isotope effect observed for the reaction of papain with the L-enantiomer in this ionization state probably rules out hydron transfer from $\mathrm{Im}^{+}-\mathrm{H}$ in the transition state (Brocklehurst et al., 1988a); $\mathrm{X}$ and $\mathrm{XH}_{2}$ states: it is convenient to relate individual ionization states such as $\mathrm{XH}, \mathrm{XH}_{2}$ etc. to an arbitrary state $\mathrm{X}$ to specify their relative stoichiometries in hydrons; in the reaction of papain with the 2-pyridyl disulphide probes the $\mathrm{X}$ state refers to the reaction at high $\mathrm{pH}$ where both (His159)- $\mathrm{Im}^{+}-\mathrm{H}$ and (Cys-25)-SH are both fully dehydronated and the 2-pyridyl group is not hydronated; the $\mathrm{XH}_{2}$ state refers to the ionization state that predominates at $\mathrm{pH}$ values around 6 , where reaction is considered to involve the $-\mathrm{S}^{-} /-\mathrm{Im}^{+} \mathrm{H}$ ion-pair form of papain and the non-hydronated form of the 2-pyridyl disulphide probe reagent; the alkaline limb of each of the pH- $k$ profiles for the reactions with these enantiomeric disulphides is of overlapping double-sigmoid form and hence there is an intermediate $\mathrm{XH}$ ionization state in which the $-\mathrm{Im}^{+}-\mathrm{H}$-assisted transition state depicted in reaction (3) is not as fully developed as in the $\mathrm{XH}_{2}$ state (see Templeton et al., 1990).

$\dagger$ For these catalysed hydrolyses, the apparent second-order rate constant for the overall acylation process $\left(k_{+2} / K_{\mathrm{s}}\right)$ is reasonably assumed to be provided by $k_{\text {cat. }} / K_{\mathrm{m}}$ (see the text); the values of $k_{\text {cat. }} / K_{\mathrm{m}}$ are those determined experimentally at pH $6.0 \mathrm{but}$ would be expected to be good approximations to the $\mathrm{pH}$-independent values (see Lowe \& Yuthavong, 1971b).

$\ddagger$ For these time-dependent inhibition reactions, the observed second-order rate constant $(k)$ provides the ratio of the first-order rate constant for covalency change $\left(k_{+2}\right)$ within an assumed enzyme-reagent adsorptive complex and the dissociation constant of the complex $\left(K_{\mathrm{r}}\right)$ (see Brocklehurst et al., 1987a, 1988a); $\tilde{k}_{+2}$ and $\tilde{K}_{\mathrm{r}}$ denote pH-independent parameters.

$\S K_{\mathrm{i}}$ denotes the equilibrium constant for the dissociation of the thiohemiacetal adduct and thus it is appropriate to compare $\left(K_{\mathrm{i}}\right)_{\mathrm{D}} /\left(K_{\mathrm{i}}\right)_{\mathrm{L}}$ with (kinetic parameter) $/$ /(kinetic parameter) $)_{\mathrm{D}}$; the values of $K_{\mathrm{i}}$ relate to $\mathrm{pH} 7.0$ and $25^{\circ} \mathrm{C}$. 

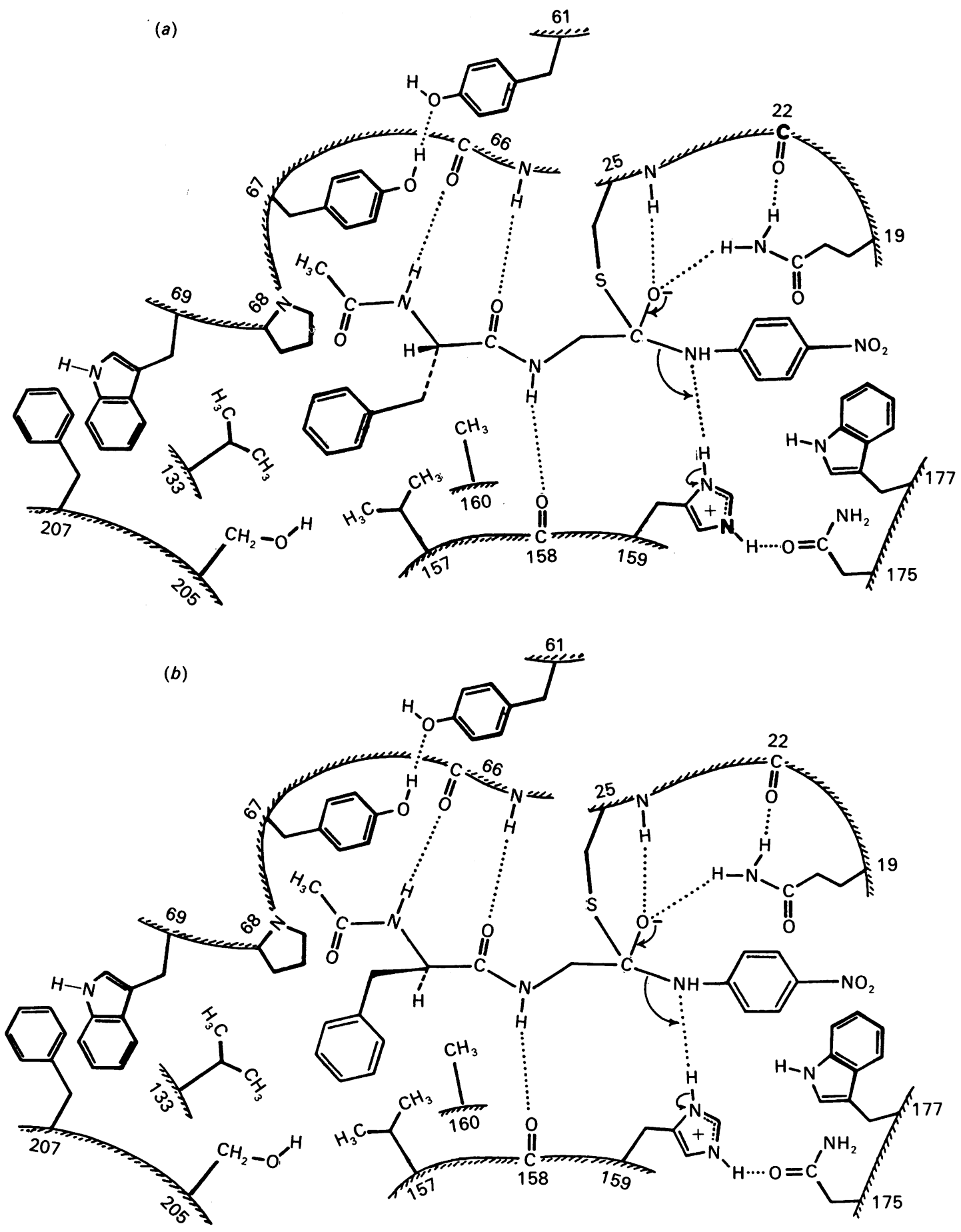

Scheme 1. Diagram showing postulated binding interactions within tetrahedral intermediates proposed to exist in the acylation of the catalytic-site thiol group of papain by $(a) N$-acetyl-L-Phe-Gly 4 -nitroanilide and $(b)$ its D-enantiomer

The drawings each show a view looking into the active-centre cleft towards the centre of the molecule with the $L$ and $R$ domains towards the top and bottom respectively of the field. Covalent bond lengths are approximately to scale but enzyme-ligand interatomic distances, e.g. in hydrogen bonds, have been exaggerated for clarity. The placing of enzyme side chains and backbone groups is not topographically correct but it shows their relative dispositions around the cleft and their approximate spatial relationships to the ligand. The structural features of the complex in and around the $S_{2}$ subsite are analogous to those deduced by Drenth et al. (1976) from X-ray-crystallographic studies on papain-inhibitor combinations such as papain alkylated on $\mathrm{S}_{(\gamma)}$ of Cys-25 by reaction with the terminal methylene group of $\mathrm{N}$-benzyloxycarbonyl-L-Phe-L-Ala-CH $\mathrm{Cl}_{2} \mathrm{Cl}$. The peptide comprising residues $P_{1}$ and $P_{2}$ lies near the extended piece of chain comprising residues 65-67 of the wall of the active-centre cleft such that the $\left(\mathrm{P}_{2}\right)-\mathrm{N}-\mathrm{H}$ and $\left(\mathrm{P}_{2}\right)>\mathrm{C}=\mathrm{O}$ groups can hydrogen-bond with the backbone $-\mathrm{C}=\mathrm{O}$ and $-\mathrm{N}-\mathrm{H}$ groups respectively of Gly-66 and the $\left(\mathrm{P}_{1}\right)-\mathrm{N}-\mathrm{H}$ group is directed towards the backbone $\mathrm{C}=\mathrm{O}$ group of Asp-158 on the opposite wall of the cleft. In the alkylated papain derivative studied by Drenth et al. (1976) and, by analogy, in the papain-L-enantiomer complex shown in $(a)$, the $\left(\mathrm{P}_{2}\right) \alpha-\mathrm{H}$ atom projects out of the protein and the $\alpha$-benzyl side chain is accommodated such that $\mathrm{C}_{(\beta)}$ lies between the side chains of Pro-68 and Ala-160, and beyond it the phenyl ring is adjacent to the side chains of Val-133 and Val-157, which 
suggestion of distortion in papain-substrate complexes by non-bonded interaction in the region of the scissile bond, which could be partly relieved in the postulated tetrahedral intermediate.

In the present work with the enantiomeric $N$-acetylPhe-Gly 4-nitroanilides, model building suggests that both enantiomers can bind to papain such that the phenyl ring of the $N$-acetyl-Phe-group makes hydrophobic contacts in the binding pocket of the $S_{2}$ subsite with preservation of the three hydrogen-bonding interactions involving (Asp-158) $>\mathrm{C}=\mathrm{O},(\mathrm{Gly}-66)>\mathrm{C}=\mathrm{O}$ and (Gly-66)-N-H (see Scheme 1). A similar conclusion was reached for the binding of the enantiomeric 2pyridyl disulphide probes (compounds I and II) (Templeton et al., 1990). In both cases the phenyl ring of the ligand can be accommodated between Val-133 and Val-157, the main difference being in the position of $\beta$ methylene group: in the papain-L-enantiomer complex (Scheme $1 a$ ) it points into the active-centre cleft and is close to Ala-160, whereas in the papain-D-enantiomer complex it points more towards solvent. It may be that the positioning of this methylene group is important for optimal binding. A $\beta$-methylene group in the $\mathrm{P}_{1}$ position of substrates for papain has been shown to contribute to both binding and acylation (Storer et al., 1988). Thus thiono esters with alanine at position $\mathrm{P}_{1}$ bind more tightly to papain than those with glycine at position $\mathbf{P}_{1}$ but acylate the enzyme more slowly. Also, when oxygen esters and thiono esters are compared, the thionoesters have larger $k_{\text {cat. }} / K_{\mathrm{m}}$ (i.e. $k_{+2} / K_{\mathrm{s}}$ ) values when glycine is at position $P_{1}$, whereas the reverse is true when alanine is at position $\mathrm{P}_{1}$ and the magnitude of the decrease in $k_{\text {cat. }} / K_{\mathrm{m}}$ on going from oxygen esters to thiono esters is similar for substrates with phenylalanine at position $P_{1}$ and those with alanine at position $P_{1}$.

If the positioning of the $\beta$-methylene group of the phenylalanine residue at position $\mathrm{P}_{2}$ does make an important contribution to binding to papain, this may contribute to the observed variation in stereochemical selectivity index (Table 2). Thus the value of the index may be related to the extent to which conformational variation of bound ligand in the catalytic-site region and in the intervening $\mathrm{S}_{1}-\mathrm{S}_{2}$ intersubsite region permits the binding mode of the $-\mathrm{CH}_{2}-\mathrm{Ph}$ group of the D-enantiomer to approach that of the L-enantiomer. For the acylation of papain and thiohemiacetal formation [reactions (1) and (4) of Table 2] the postulated existence of an oxyanion hole in papain may be relevant. The role of this structural feature, postulated on the basis of crystallographic evidence (Drenth et al., 1976) and contributing (Gln19) $-\mathrm{NH}_{2}$ and (Cys-25)- $\mathrm{N}-\mathrm{H}$ as hydrogen-bond donors (see Scheme 1) in the catalytic mechanism of papain, remains controversial. Asbóth et al. (1985) suggested that it may not be operative in the acylation step, but recent protein engineering experiments (Storer et al., 1989) provide evidence that it does have a role in catalysis (A. C. Storer, personal communication), although possibly not in the deacylation of dithioacyl-papains (Storer et al., 1988). The acylation reaction is depicted in reaction (1) of Table 2 and in Scheme 1 as involving the ratelimiting general acid-catalysed elimination of the leaving group from an anionic tetrahedral intermediate, which would be predicted from the negative Hammett rho value found for the dependence of $k_{+2}$ on leaving group structure in substituted $N$-acetyl-L-Phe-Gly anilides (Lowe \& Yuthavong, 1971b). The existence of considerable conformational constraints imposed by the array of hydrogen-bonding interactions in the oxyanion hole and the $S_{1}-S_{2}$ intersubsite region (Scheme 1), coupled with the requirements for efficient general acid-catalysed expulsion of the leaving group, might predict the relatively strict stereochemical selectivity reported in Tables 1 and 2 if the binding mode of the $-\mathrm{CH}_{2}-\mathrm{Ph}$ side chain makes the rather precise demands discussed above. In thiohemiacetal formation [reaction (4) of Table 2], no requirements for catalysed leaving-group expulsion need to be met, and this and the possibility that the adduct may not need to bind in the oxyanion hole (Mackenzie et al., 1986) may combine to produce the very small value (5) for the stereochemical selectivity index (Table 2). For the reaction of papain with the 2-pyridyl disulphides [reactions (2) and (3) of Table 2] the greater flexibility (provided by the additional methylene group and the disulphide bond) in the region of the electrophilic centre might account for the lower stereochemical selectivity than that for the reactions of the 4-nitroanilides. The fact that the value of the index (Table 2) is not much different when the binding must provide for association of the leaving group with (His-159)- $\mathrm{Im}^{+}-\mathrm{H}$ [reaction (3)] than when this constraint does not exist [reaction (2)], however, is surprising. This result serves to emphasize that, although some of the factors that define the interrelationship of binding and catalytic-site chemistry in papain have been delineated (see Brocklehurst et al., 1988b; Kowlessur et al., 1989), others remain to be identified.

We thank the Science and Engineering Research Council for project grants and for an Earmarked Studentship for D. K., Miss Liz Wilkie for skilled technical assistance, and Miss Joy Smith for the expert production of the typescript.

\section{REFERENCES}

Asbóth, B., Stokum, E., Khan, I. U. \& Polgár, L. (1985) Biochemistry 24, 606-609

Bender, M. L. \& Kézdy, F. J. (1965) Annu. Rev. Biochem. 34, 49-76

with Tyr-67, Trp-69 and Phe-207 form the hydrophobic binding pocket. The $\mathrm{N}$ atom of the 4-nitroaniline leaving group is shown in hydrogen-bonding interaction with the imidazolium side chain of His-159, which is considered to provide general acid catalysis of the elimination step to provide acyl-enzyme (thiolester) intermediate. The oxyanion derived from the carbonyl $O$ atom of the anilide substrate is shown accepting hydrogen bonds from the backbone $-\mathrm{N}-\mathrm{H}$ of Cys- 25 and the amide side chain of Gln-19 (Drenth et al., 1976) of the putative oxyanion hole. In the papain-D-enantiomer complex shown in (b) all four hydrogen bonds can be maintained, and even though the $\left(\mathrm{P}_{2}\right) \alpha-\mathrm{H}$ atom projects into the protein the $\alpha$-benzyl side chain can still be accommodated either close to the region in the $S_{2}$ subsite occupied by this side chain in the complex with the $L$-enantiomer [see $(a)$ ] or by rotation about $\mathrm{C}_{(\alpha)}-\mathrm{C}_{(\beta)}$, with the phenyl ring close to Tyr-67. In its rotated position (not shown) the phenyl ring points away from the centre of the papain molecule and towards the L domain [see Templeton et al. (1990) for a drawing of the analogous complex of papain and the 2-pyridyl disulphide (D-enantiomer) (compound II)]. 
Berger, A. \& Schechter, I. (1970) Philos. Trans. R. Soc. London B 257, 249-264

Brocklehurst, K. (1977) Biochem. J. 163, 111-116

Brocklehurst, K. (1979) Biochem. J. 181, 775-778

Brocklehurst, K. \& Cornish-Bowden, A. (1976) Biochem. J. 159, 165-166

Brocklehurst, K. \& Little, G. (1973) Biochem. J. 133, 67-80

Brocklehurst, K., Crook, E. M. \& Wharton, C. W. (1968) FEBS Lett. 2, 69-73

Brocklehurst, K., Kowlessur, D., O'Driscoll, M., Patel, G., Quenby, S., Salih, E., Templeton, W., Thomas, E. W. \& Willenbrock, F. (1987a) Biochem. J. 244, 173-181

Brocklehurst, K., Willenbrock, F. \& Salih, E. (1987b) New Compr. Biochem. 16, 39-158

Brocklehurst, K., Kowlessur, D., Patel, G., Templeton, W., Quigley, K., Thomas, E. W., Wharton, C. W., Willenbrock, F. \& Szawelski, R. J. (1988a) Biochem. J. 250, 761-772

Brocklehurst, K., Brocklehurst, S. M., Kowlessur, D., O'Driscoll, M., Patel, G., Salih, E., Templeton, W., Thomas, E., Topham, C. M. \& Willenbrock, F. (1988b) Biochem. J. 256, 543-555

Dixon, W. J. (chief ed.), Brown, M. B., Engelman, L., Hill, M. A. \& Jennrich, R. I. (1988) BMDP Statistical Software, pp. 389-417, University of California Press, Guildford, U.K.
Drenth, J., Kalk, K. H. \& Swen, H. M. (1976) Biochemistry 15, 3731-3738

Erlanger, B. F., Kokowsky, N. \& Cohen, W. (1961) Arch. Biochem. Biophys. 95, 271-278

Fersht, A. (1977) Enzyme Structure and Mechanism, pp. 96-97, W. H. Freeman and Co., Reading

Kowlessur, D., Topham, C. M., Thomas, E. W., O'Driscoll, M., Templeton, W. \& Brocklehurst, K. (1989) Biochem. J. 258, 755-764

Lowe, G. (1976) Tetrahedron 32, 291-302

Lowe, G. \& Yuthavong, Y. (1971a) Biochem. J. 124, 107115

Lowe, G \& Yuthavong, Y. (1971b) Biochem. J. 124, 117122

Mackenzie, N. E., Grant, S. K., Scott, I. A. \& Malthouse, J. P. G. (1986) Biochemistry 25, 2293-2298

Storer, A. C., Angus, R. H. \& Carey, P. R. (1988) Biochemistry 27, 264-268

Storer, A. C., Khouri, H., Menard, R., Tessier, D. C., Thomas, D. Y. \& Vernet, T. (1989) Proc. U.C.L.A. Symp. (Salt Lake City) p. 79

Templeton, W., Kowlessur, D., Thomas, E. W., Topham, C. M. \& Brocklehurst, K. (1990) Biochem. J. 266, 645-651

Wilkinson, G. N. (1961) Biochem. J. 80, 324-332

Received 23 August 1989; accepted 6 October 1989 